\title{
(6) OPEN ACCESS \\ Occurrence of mental health symptoms and disorders in current and former elite athletes: a systematic review and meta-analysis
}

\author{
Vincent Gouttebarge, ${ }^{\oplus 1,2}$ João Mauricio Castaldelli-Maia, ${ }^{\oplus 3,4}$ Paul Gorczynski, $^{5}$ \\ Brian Hainline, ${ }^{\oplus 6}$ Mary E Hitchcock, ${ }^{7}$ Gino M Kerkhoffs, ${ }^{1,2,8}$ Simon M Rice, ${ }^{9,10}$ \\ Claudia L Reardon ${ }^{\odot 11,12}$
}

\begin{abstract}
- Additional material is published online only. To view please visit the journal online (http://dx.doi.org/10.1136/ bjsports-2019-100671)
\end{abstract}

For numbered affiliations see end of article.

\section{Correspondence to Dr Vincent Gouttebarge, Amsterdam UMC, Univ of Amsterdam, Department of Orthopaedic Surgery, Amsterdam, The Netherlands; v.gouttebarge@amsterdamumc.}

Received 5 February 2019 Revised 1 April 2019 Accepted 3 April 2019 Published Online First 14 June 2019
Check for updates

(C) Author(s) (or their employer(s)) 2019. Re-use permitted under CC BY. Published by BMJ.

\section{To cite: Gouttebarge V,} Castaldelli-Maia JM, Gorczynski P, et al. $\mathrm{Br} J$ Sports Med 2019:53:700-707.

\begin{abstract}
Objectives To present an overview of the existing epidemiological evidence regarding the occurrence of mental health symptoms and disorders among current and former elite athletes.
\end{abstract}

Design Systematic review and meta-analysis.

Data sources Five electronic databases were searched from inception to November 2018: PubMed (MEDLINE) SportDiscus via EBSCO, PSycINFO via ProQuest, Scopus and Cochrane.

Eligibility criteria for selecting studies We included original quantitative studies that were written in English, were conducted exclusively among current or former elite athletes, and presented incidence or prevalence rates of symptoms of mental disorders. Results Twenty-two relevant original studies about mental health symptoms and disorders among current elite athletes were included: they presented data especially on symptoms of distress, sleep disturbance, anxiety/depression and alcohol misuse. Meta-analyses comprising 2895 to 5555 current elite athletes showed that the prevalence of mental health symptoms and disorders ranged from $19 \%$ for alcohol misuse to $34 \%$ for anxiety/depression. Fifteen relevant original studies about mental health symptoms and disorders among former elite athletes were included: they similarly presented data especially about symptoms of distress, sleep disturbance, anxiety/depression and alcohol misuse. Meta-analyses comprising 1579 to 1686 former elite athletes showed that the prevalence of mental health symptoms and disorders ranged from $16 \%$ for distress to 26\% for anxiety/depression.

Conclusions Our meta-analyses showed that the prevalence of mental health symptoms and disorders ranged from $19 \%$ for alcohol misuse to $34 \%$ for anxiety/ depression for current elite athletes, and from 16\% for distress to $26 \%$ for anxiety/depression for former elite athletes.

\section{INTRODUCTION}

Mental health symptoms and disorders (eg, those involving distress, anxiety, depression or substance misuse) are more frequently reported in young adult populations than in other age groups. ${ }^{1-3} \mathrm{~A}$ recent systematic review and meta-analysis showed that one out of five adults experienced a mental health disorder within the past 12 months and almost one out of three across their lifetime. ${ }^{4}$ In the past decade, mental health symptoms and disorders have been increasingly under study in elite athletes. Single studies show that the prevalence of mental health symptoms and disorders among both current and former elite athletes seems substantial and similar to the prevalence in the general population. ${ }^{5}$ A professional or elite sport career is characterised by more than 640 distinct stressors that could induce mental health symptoms and disorders. ${ }^{6}$ Furthermore, transitioning out of sport can be a difficult period for athletes with an increased likelihood of developing mental health symptoms and disorders. ${ }^{67}$ At the present time, an overview of the available scientific evidence about the extent of mental health symptoms and disorders in elite athletes is lacking. Therefore, we aimed to review the existing epidemiological evidence regarding the occurrence of mental health symptoms and disorders among current and former elite athletes.

\section{METHODS}

A systematic review of the scientific literature was conducted in accordance with Preferred Reporting Items for Systematic Reviews and Meta-Analyses (PRISMA) guidelines.

\section{Data sources and search strategy}

Five electronic databases were searched from inception to November 2018: PubMed (MEDLINE), SportDiscus via EBSCO, PSycINFO via ProQuest, Scopus and Cochrane. We applied the following filters (if applicable): Humans; English. A highly sensitive search strategy (included in Appendix 1) was built based on two groups of keywords (and related search terms): 'mental health disorders' and 'elite athletes'. Within each keyword, all search terms were combined by the Boolean command OR, and the keywords (and respective search terms) were linked by the Boolean command AND. Existing medical subject headings $(\mathrm{MeSH})$ were used if possible, and search terms were truncated with *.

\section{Eligibility criteria and study selection}

Eligibility criteria for inclusion were:

1. The study population consists exclusively of current or former elite athletes (defined as professional or Olympic athletes).

2. The study outcome is presented as incidence or prevalence of mental health symptoms and disorders. 
3. The article presents an original quantitative study.

4. The article is written in English.

To identify potentially relevant articles, titles and abstracts were screened independently by two researchers (VG, GK) using the eligibility criteria. If the title and abstract did not provide sufficient information to determine whether the eligibility criteria were met, it was included for full text review. Then, all full text articles were assessed independently by two researchers (VG, GK) using the eligibility criteria. To avoid missing any relevant publications, the references of the included studies were screened. Any disagreements regarding the inclusion or exclusion of articles were resolved by consulting a third researcher (CR).

\section{Data extraction}

Data from the included articles were extracted and crosschecked by two authors (JMC-M, SR). Two standardised extraction forms were used (one for current elite athletes and one for former elite athletes) in order to report the following: study information (author, year); study population (eg, sample size, age, gender, height, weight, country, type and level of sport, duration of sport career, time since retirement); study design and related information (follow-up, response rate, loss to follow-up); definition and assessment of mental health symptoms and disorders; and outcome expressed as incidence or prevalence.

\section{Risk of bias}

To describe the risk of bias of the included studies, a 9-item tool for prevalence studies was used (included in Appendix 2). ${ }^{9}$ Each of the nine potential bias domains was rated as low (0) or high (1) risk of bias. ${ }^{9}$ Based on the total score, a study was rated as follows: low risk of bias with score of 0 to 3 ; moderate risk of bias with score of 4 to 6 ; and high risk of bias with score of 7 to 9. ${ }^{9}$ The risk of bias of all included articles was assessed by two authors (VG, GK), with any discrepancies resolved through consensus among the authors.

\section{Meta-analysis}

All statistical analyses were conducted separately for current and former elite athletes in OpenMetaAnalyst. ${ }^{10}$ Random-effects models were applied to all meta-analyses to account for heterogeneity. The random-effects method was chosen because of its conservative summary estimate and because it incorporates between- and within-study variance. ${ }^{11}$ Pooled estimates with 95\% confidence intervals (CI) were calculated for the prevalence of mental health symptoms and disorders. Variance between studies was assessed using Cochran's Q and reported as $\wedge^{\wedge}$. Visual inspection of funnel plots assessed the degree of potential publication bias.

\section{RESULTS}

Search strategy

A total of 1659 potentially relevant citations were retrieved. After removing 751 duplicates, 908 citations remained. After applying the inclusion criteria to the titles and abstracts, 85 potentially relevant studies were included for full text review. From these, 54 studies were excluded for various reasons (not in English: $\mathrm{n}=1$; not an original study: $\mathrm{n}=5$; not including only current or former elite athletes: $n=22$; not presenting an adequate outcome measure: $n=26$ ). The reference check of the included studies resulted in three additional relevant studies. ${ }^{12-14}$ Consequently, our systematic review includes 34 original studies: 18 including exclusively current elite athletes, ${ }^{12} 13$ 15-30 11 including exclusively former elite athletes ${ }^{31-41}$ and four including both current and former elite athletes. ${ }^{14} 42-44$ The PRISMA flow chart of the search procedure is presented as figure 1 .

\section{Risk of bias}

Thirty-three of the 34 original studies included in our systematic review had an overall low risk of bias, and one study had a moderate risk of bias (included in Appendix 3).

\section{Mental health symptoms and disorders among current elite athletes}

Twenty-two studies reporting mental health symptoms and disorders among current elite athletes were included, presenting data (mostly prevalence) most commonly for symptoms of distress, sleep disturbance, anxiety/depression and alcohol misuse (included in online supplementary appendix 4). ${ }^{12-3042-44}$ Among those, 11 studies reported prevalence data on distress symptoms among 3335 male and female elite athletes (age ranging from 16 to 29 years) from team sports (eg, cricket, football, handball, ice hockey, rugby) and combined Olympic sports (eg, boxing, gymnastics, judo, rowing, swimming)..$^{12-14161921232542-44}$ Based on our meta-analysis, we found that $19.6 \%$ (95\%CI: 16.0 to 23.3 ) of elite athletes reported symptoms of distress (high between-study heterogeneity: $\left.\mathrm{Q}=77.1, \mathrm{P}<0.001, \wedge_{2}=85.7 \%\right)$. Ten studies reported prevalence data on symptoms of sleep disturbance among 4782 elite athletes from various sports: ${ }^{12-16} 2123294344$ meta-analysis revealed that $26.4 \%$ (95\%CI: 21.6 to 31.2 ) of elite athletes reported symptoms of sleep disturbance (high betweenstudy heterogeneity: $\left.\mathrm{Q}=133.651, \mathrm{P}<0.001,{ }^{\wedge} 2=92.518 \%\right)$. Nine studies reported prevalence data on symptoms of anxiety/ depression (not differentiated) among 2895 elite athletes from various sports: ${ }^{12-14} \quad 1921 \quad 23 \quad 42-44$ meta-analysis showed that $33.6 \%$ (95\%CI: 27.4 to 39.7 ) of elite athletes reported symptoms of anxiety/depression (high between-study heterogeneity: $\mathrm{Q}=109.737, \mathrm{P}<0.001, \wedge 2=91.799 \%)$. Eleven studies reported prevalence data on symptoms of alcohol misuse among 5555 elite athletes from various sports: ${ }^{12-14} 172123262942-44$ meta-analysis revealed that $18.8 \%$ (95\%CI: 11.1 to 26.5 ) of elite athletes reported symptoms of alcohol misuse (high between-study heterogeneity: $\left.\mathrm{Q}=910.896, \quad \mathrm{P}<0.001, \wedge_{2}=98.792 \%\right)$. All meta-analyses and pooled estimates for data in current elite athletes are presented in figure 2 . Other cross-sectional studies presented data for eating disorders or adverse eating habits $(n=7$; $1 \%-28 \%),{ }^{18202325272930}$ for panic disorder $(n=2 ; 1 \%-5 \%)^{2529}$ and for gambling $(n=1 ; 2 \%-7 \%) .{ }^{26}$ Only six prospective cohort studies were retrieved from the literature, showing incidence (new cases over 6-12 months) from 6\% for symptoms of alcohol misuse to $57 \%$ for symptoms of anxiety/depression. ${ }^{131421222443}$ One single study was conducted solely in female elite athletes (distance runners), showing a prevalence of eating disorders from $1 \%$ for bulimia nervosa to $4 \%$ for anorexia nervosa. ${ }^{27}$

\section{Mental health symptoms and disorders among former elite athletes}

Fifteen studies reporting mental health symptoms and disorders among former elite athletes were included, presenting data (mostly prevalence) most commonly for symptoms of distress, sleep disturbance, anxiety/depression and alcohol misuse (included in online supplementary appendix 5). ${ }^{14}$ 31-44 Among those, eight studies reported prevalence data on distress symptoms among 1686 former male and female elite athletes (age ranging from 34 to 62 years) from team sports (American Football, cricket, football, ice hockey, rugby) and combined Olympic 

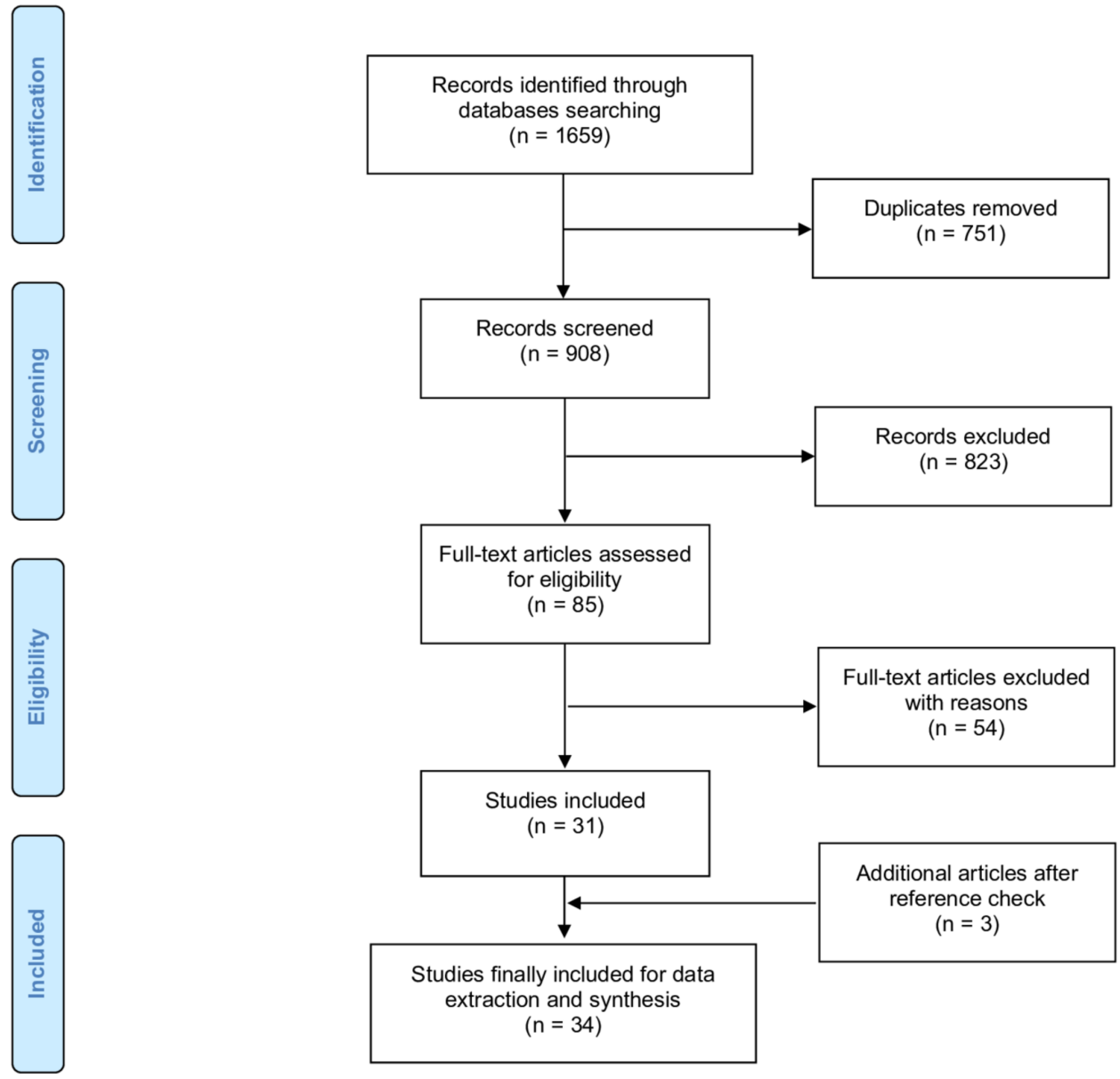

Figure 1 Flow chart of the search procedure.

sports. ${ }^{14} 31$ 33-35 42-44 Meta-analysis demonstrated that $15.8 \%$ (95\% CI: 16.0 to 23.3 ) of former athletes reported symptoms of distress (high between-study heterogeneity: $Q=55.502$, $\mathrm{P}<0.001, \wedge 2=85.586 \%)$. Seven studies reported prevalence data on symptoms of sleep disturbance among 1579 former elite athletes from various sports, ${ }^{143133-354344}$ and meta-analysis showed that 20.9\% (95\%CI: 15.2 to 26.6) of former athletes reported symptoms of sleep disturbance (high between-study heterogeneity: $\left.\mathrm{Q}=57.432, \mathrm{P}<0.001, \wedge_{2}=87.812 \%\right)$. Eight studies reported prevalence data on symptoms of anxiety/depression (not differentiated) among 1662 former elite athletes from various sports, ${ }^{14} 31$ 33-35 42-44 with meta-analysis demonstrating that $26.4 \%$ (95\%CI: 21.4 to 31.4 ) of former athletes reported symptoms of anxiety/depression (high between-study heterogeneity: $\left.\mathrm{Q}=43.320, \mathrm{P}<0.001, \wedge_{2}=81.533 \%\right)$. Eight studies reported prevalence data on symptoms of alcohol misuse among 1636 former athletes from various sports: ${ }^{143133-3542-44}$ meta-analysis revealed that 21.1\% (95\%CI: 14.7 to 27.4) of former athletes reported symptoms of alcohol misuse (high betweenstudy heterogeneity: $\left.\mathrm{Q}=93.395, \quad \mathrm{P}<0.001, \quad \wedge_{2}=91.434 \%\right)$. All meta-analyses and pooled estimates for data in former elite athletes are presented in figure 3. Other cross-sectional studies presented data for eating disorders $(n=2 ; 24 \%-27 \%),{ }^{35}$ for dementia $(n=1 ; 6 \%),{ }^{36}$ for Alzheimer's disease $(n=1 ; 12 \%)^{36}$ and for mild cognitive impairment $(n=1 ; 23 \%){ }^{36}$ Only five prospective cohort studies were retrieved from the literature, showing incidence (new cases over 6-12 months) from 0\% for symptoms of distress and anxiety/depression to $42 \%$ for symptoms of depression. ${ }^{1431374043}$

\section{DISCUSSION}

We reviewed the existing epidemiological evidence regarding the occurrence of mental health symptoms and disorders among current and former elite athletes. Our search strategies and study selection retrieved 34 original studies, 33 of which had an overall low risk of bias. Among both current and former elite athletes, specific data about symptoms of distress, sleep disturbance, anxiety/ depression and alcohol misuse were presented. Our meta-analyses showed that the prevalence of mental health symptoms and disorders ranged from 19\% for alcohol misuse to 34\% for anxiety/ depression for current elite athletes, and from $16 \%$ for distress to $26 \%$ for anxiety/depression for former elite athletes.

The number of epidemiologic studies addressing mental health symptoms and disorders among current and former elite athletes has been increasing: 32 of the 34 studies included in our review were published after 2010. Relying primarily on self-reported cross-sectional data (and thus not on clinically diagnosed data), these studies and related meta-analyses suggest that the prevalence of symptoms of distress, sleep disturbance and anxiety/ depression is higher in current athletes than in former athletes. This might be explained because during their sport career, elite athletes are exposed to generic factors such as adverse life events but also to sport-specific stressors. ${ }^{6}{ }^{45}$ For instance, a greater overall risk of mental health symptoms and disorders might be experienced by elite athletes with severe musculoskeletal injuries, multiple surgeries, decreased sport performance or maladaptive perfectionism. $^{24} 43$ 46-50 Prevalence of alcohol misuse calculated in our meta-analyses was similar among current and former elite 
Drew M, Vlahovich N, Hughes D, et al. 2018 Foskett RL, Longstaff F 2018

Gouttebarge V, Aoki H, Kerkhoffs G. 2015 Gouttebarge V, Frings-Dresen MH, Sluiter JK. 2015 Gouttebarge V, Tol J, Kerkhoffs G, 2016 Gouttebarge V, Hopley P, Kerkhoffs G, et al. 2017 Gouttebarge V, Jonkers R, Moen M, et al. 2017 Gouttebarge V, Kerkhoffs G. 2017

Gulliver A, Griffiths KM, Mackinnon A, et al. 2015 Kilic ., Aoki H, Haagensen R, et al. (Football) 2017 Kilic ., Aoki H, Haagensen R, et al. (Handball) 2017 Schuring N, Kerkhoffs G, Gray J, et al. 2017

Overall $\left(\left.\right|^{\wedge} 2=8573 \%, P<0.001\right)$
$0.142(0.081,0.202)$ $0.232(0.163,0.302)$ $0.148(0.118,0.178)$ $0.101(0.052,0.149)$ $0.383(0.313,0.452)$ $0.175(0.151,0.199)$ $0.266(0.203,0.328)$ $0.134(0.077,0.192)$ $0.165(0.117,0.214)$ $0.147(0.109,0.184)$ $0.198(0.147,0.250)$ $0.384(0.272,0.495)$

$0.196(0.160,0.233)$

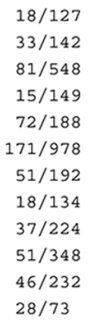

$621 / 3335$

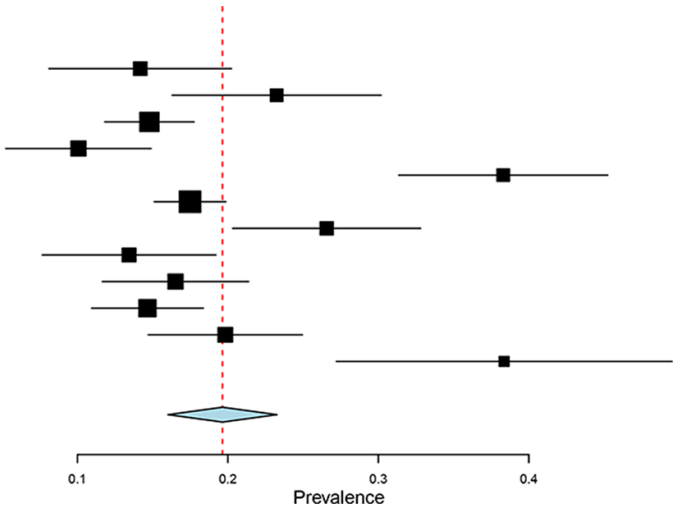

Studies

Estimate (95\% C.I.) Events/Total

Biggins M, Cahalan R, Comyns T, et al. 2017 Drew M, Vlahovich N, Hughes D, et al. 2018 Gouttebarge V, Aoki H, Kerkhoffs G. 2015 Gouttebarge V, Tol J, Kerkhoffs G. 2016

Gouttebarge V, Hopley P, Kerkhoffs G, et al. 2017 Gouttebarge V, Jonkers R, Moen M, et al. 2017 Gouttebarge V, Kerkhoffs G. 2017

Kilic $\mathrm{O}$, Aoki H, Haagensen $\mathrm{R}$, et al. (Football) 2017 Kilic O, Aoki H, Haagensen R, et al. (Handball) 2017 Schuring N, Kerkhoffs G, Gray J, et al. 2017 Schaal K, Tafflet M, Nassif H, et al. 2011

$0.478(0.360,0.596)$ $0.490(0.394,0.586)$ $0.234(0.198,0.269)$ $0.330(0.263,0.397)$ $0.129(0.107,0.150)$ $0.223(0.164,0.283)$ $0.150(0.090,0.211)$ $0.222(0.170,0.273)$ $0.220(0.167,0.273)$ $0.384(0.272,0.495)$ $0.215(0.197,0.233)$ Overall $\left(\left.\right|^{\wedge} 2=9252 \%, P<0.001\right)$ $0.264(0.216,0.312)$

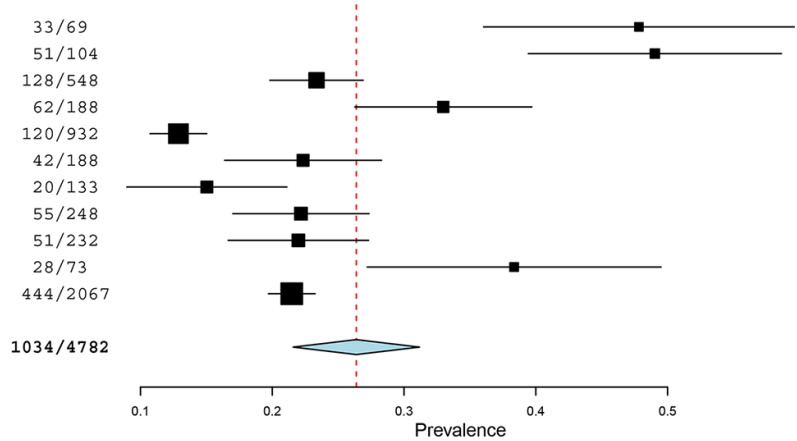

Foskett RL, Longstaff F 2018

$0.478(0.395,0.562)$

Gouttebarge V, Aoki H, Kerkhoffs G. 2015 $0.379(0.336,0.422)$ Gouttebarge V, Frings-Dresen MH, Sluiter JK. $2015 \quad 0.255 \quad(0.185,0.325)$ Gouttebarge V, Tol J, Kerkhoffs G. 2016 Gouttebarge V. Hopley P, Kerkhoffs G, et al. $2017 \quad 0.299 \quad(0.270,0.328)$ Gouttebarge V, Jonkers R, Moen M, et al. $2017 \quad 0.447(0.376,0.518)$ Gouttebarge V, Kerkhoffs G. 2017 $0.241(0.168,0.313)$ Kilic O, Aoki H, Haagensen R, et al. (Football) $2017 \quad 0.181 \quad(0.141,0.221)$ Kilic O, Aoki H, Haagensen R, et al. (Handball) $2017 \quad 0.263 \quad(0.206,0.320)$ Schuring N, Kerkhoffs G, Gray J, et al. $2017 \quad 0.370 \quad(0.259,0.481)$

$66 / 138$ $187 / 493$ $38 / 149$ $87 / 182$ $287 / 959$ $84 / 188$ $32 / 133$

$63 / 348$ $61 / 232$ $27 / 73$ $932 / 2895$

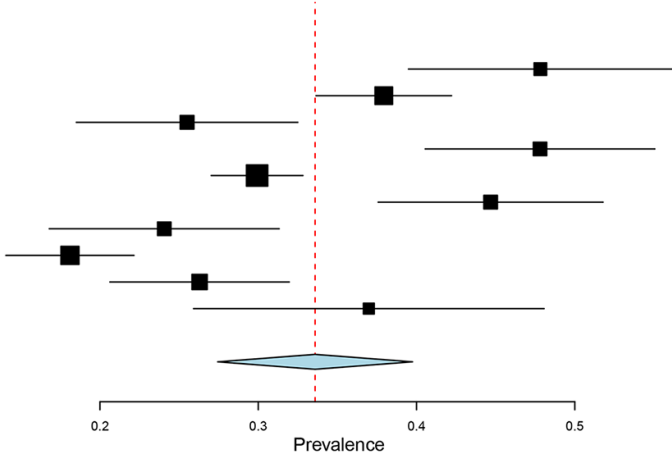

Studies

du Preez EJ, Graham KS, Gan TY, et al. 2017 Gouttebarge V, Aoki H, Kerkhoffs G. 2015 Gouttebarge V, Frings-Dresen MH, Sluiter JK. 2015 Gouttebarge V, Tol J, Kerkhoffs G. 2016 Gouttebarge V, Hopley P, Kerkhoffs G, et al. 2017 Gouttebarge V, Jonkers R, Moen M, et al. 2017 Gouttebarge V, Kerkhoffs G. 2017 Hakanssona, et al. 2018

Kilic O, Aoki H, Haagensen R, et al. (Football) 2017 Kilic O, Aoki H, Haagensen R, et al. (Handball) 2017 Schaal K, Tafflet M, Nassif H, et al. 2011 Schuring N, Kerkhoffs G, Gray J, et al. 2017

Estimate (95\% C.I.) Events/Tota $0.686(0.638,0.733)$ $0.094(0.069,0.119)$ $0.188(0.125,0.251)$ $0.232(0.169,0.294)$ $0.153(0.130,0.176)$ $0.064(0.029,0.099)$ $0.076(0.031,0.121)$ $0.259(0.213,0.305)$ $0.029(0.011,0.046)$ $0.026(0.005,0.046)$ $0.209(0.191,0.227)$ $0.260(0.160,0.361)$

Overall (I^2=9879\%, P< 0.001)

$0.188(0.111,0.265)$

Figure 2 Meta-analyses and pooled estimates for current elite athletes. 2A: symptoms of distress; 2B: symptoms of sleep disturbance; 2C: symptoms of anxiety/depression; 2D: symptoms of alcohol misuse. 


\section{Systematic review}

Studies

Brown JC, Kerkhoffs G, Lambert MI, et al. 2017 Gouttebarge V, Frings-Dresen MH, Sluiter JK. 2015 Gouttebarge V, Aoki H, Kerkhoffs G. 2016 Gouttebarge V, Kerkhoffs, G, Lambert M. 2016 Gouttebarge V, Jonkers R, Moen M, et al. 2017 Gouttebarge V, Kerkhoffs G. 2017

Kilic O, Aoki H, Haagensen R, et al. (Football) 2017 Kilic O, Aoki H, Haagensen R, et al. (Handball) 2017 Schuring N, Kerkhoffs G, Gray J, et al. 2017

Overall $\left(\left.\right|^{\wedge} 2=8559 \%, P<0.001\right)$
Estimate (95\% C.I.) Events/Total

$0.070(0.038,0.102)$ $0.183(0.108,0.257)$ $0.184(0.132,0.237)$ $0.248(0.197,0.299)$ $0.179(0.134,0.223)$ $0.117(0.057,0.177)$ $0.087(0.052,0.121)$ $0.163(0.108,0.218)$ $0.263(0.123,0.403)$

$0.158(0.113,0.203)$

$17 / 243$ $19 / 104$ $38 / 206$ $69 / 278$ $50 / 280$ $13 / 111$ $22 / 254$ $28 / 172$ $10 / 38$

$266 / 1686$

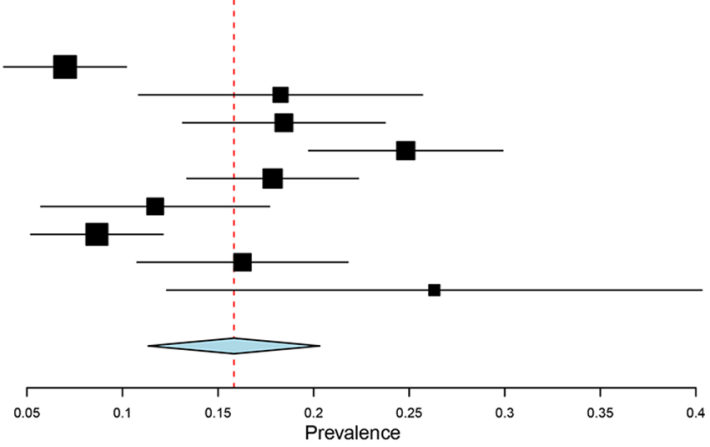

Estimate (95\% C.I.) Events/Total

Studies

Brown JC, Kerkhoffs G, Lambert MI, et al. 2017 Gouttebarge V, Aoki H, Kerkhoffs G. 2016 Gouttebarge V, Kerkhoffs, G, Lambert M. 2016 Gouttebarge V, Jonkers R, Moen M, et al. 2017 Gouttebarge V, Kerkhoffs G. 2017

Kilic O, Aoki H, Haagensen R, et al. (Football) 2017 Kilic O, Aoki H, Haagensen R, et al. (Handball) 201 Schuring N, Kerkhoffs G, Gray J, et al. 2017

Overall $\left(\left(^{\wedge} 2=8781 \%, P<0.001\right)\right.$
$0.284(0.231,0.337)$ $0.282(0.220,0.343)$ $0.288(0.231,0.345)$ $0.218(0.170,0.266)$ $0.167(0.096,0.237)$ $0.110(0.072,0.149)$ $0.122(0.073,0.171)$ $0.211(0.081,0.340)$

$0.209(0.152,0.266)$

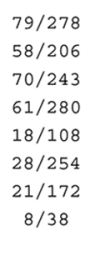

$343 / 1579$
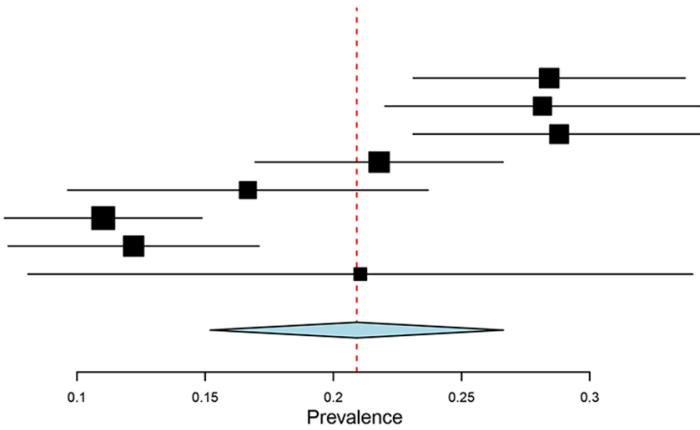

Studies

Estimate (95\% C.I.) Events/Total

Brown JC, Kerkhoffs G, Lambert MI, et al. 2017

$0.288(0.231,0.345)$ Gouttebarge V, Frings-Dresen MH, Sluiter JK. $2015 \quad 0.394 \quad(0.300,0.488)$ Gouttebarge V, Aoki H, Kerkhoffs G. 2016 $0.353(0.284,0.421)$ $0.284(0.231,0.337)$ Gouttebarge V, Kerkhoffs, G, Lambert M. 2010 $\begin{array}{lllll}\text { Gouttebarge V, Jonkers R, Moen M, et al. } 2017 & 0.294 & (0.241, & 0.348) \\ \text { Gouttebarge V, Kerkhoffs G. } 2017 & 0.194 & (0.120, & 0.269)\end{array}$ Kilic O, Aoki H, Haagensen R, et al. (Football) $2017 \quad 0.187 \quad\left(\begin{array}{lll}0.138 & 0.235)\end{array}\right.$ Kilic O, Aoki H, Haagensen R, et al. (Handball) $2017 \quad 0.158 \quad(0.103,0.213)$ Schuring N, Kerkhoffs G, Gray J, et al. 2017 $0.243(0.105,0.381)$ Overall $\left(\left.\right|^{\wedge} 2=8153 \%, P<0.001\right)$

$70 / 243$ $41 / 104$ $66 / 187$ $79 / 278$ $83 / 282$ $21 / 108$ $47 / 252$ $27 / 171$ $9 / 37$

$443 / 1662$

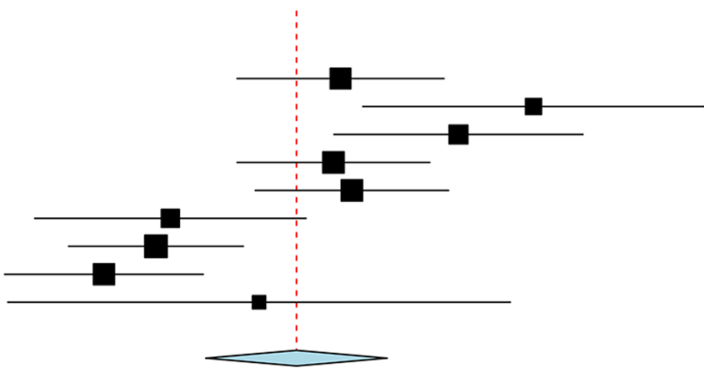

Studies

Brown JC, Kerkhoffs G, Lambert MI, et al. 2017 Gouttebarge V, Frings-Dresen MH, Sluiter JK. 2015 Gouttebarge V, Aoki H, Kerkhoffs G. 2016 Gouttebarge V, Kerkhoffs, G, Lambert M. 2016 Gouttebarge V, Jonkers R, Moen M, et al. 2017 Gouttebarge V, Kerkhoffs G. 2017

Kilic O, Aoki H, Haagensen R, et al. (Football) 2017 Kilic O, Aoki H, Haagensen R, et al. (Handball) 2017 Schuring N, Kerkhoffs G, Gray J, et al. 2017

Overall $\left(I^{\wedge} 2=9143 \%, P<0.001\right)$
Estimate (95\% C.I.) Events/Total

$0.238(0.181,0.295)$ $0.317(0.228,0.407)$ $0.246(0.187,0.306)$ $0.238(0.188,0.289)$ $0.232(0.182,0.282)$ $0.287(0.202,0.372)$

$0.084(0.049,0.118)$ $0.222(0.086,0.358)$

$0.211(0.147,0.274)$

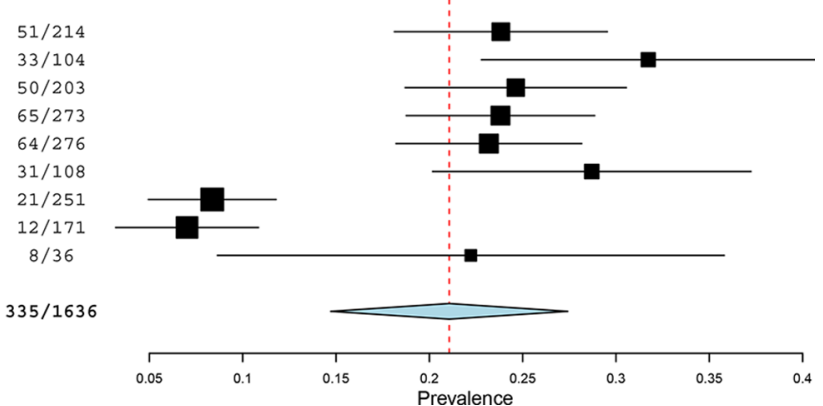

Figure 3 Meta-analyses and pooled estimates for former elite athletes 3A: symptoms of distress; 3B: symptoms of sleep disturbance; 3C: symptoms of anxiety/depression; 3D: symptoms of alcohol misuse.

athletes, namely $19 \%$ vs $21 \%$, respectively. This is surprising because our expectation was that alcohol misuse would be less prevalent in current athletes than in former athletes, as it would be expected to negatively impact performance and recovery. A potential explanation for this similar prevalence of alcohol misuse in current and former elite athletes might be 
that substantial alcohol use might be normative in some sports contexts (eg, binge pattern of use during the off-season), while alcohol misuse in former elite athletes might be the consequence of transitioning distress, lack of meaningful substitute activities or 'self-treatment' of enduring physical complaints related to prior injuries. Higher values of sleep disturbance prevalence were found in current elite athletes when compared with former elite athletes ( $26 \%$ vs $21 \%$, respectively), and is likely to impair performances and recovery. Pre-competition stress, night-time sports events, early morning training and travel can contribute to these high values. ${ }^{15} 16$

Our systematic review and related meta-analyses suggest that the prevalence of mental health symptoms and disorders in current and former elite athletes (16\%-34\%) may be slightly higher than in the general population. However, it remains difficult to compare the substantial prevalence found in these current and former elite athletes because of the absence of reference groups from the general population in all studies included in our meta-analyses. A recent systematic review and meta-analysis study performed across 155 general populations in 59 countries indicated that $20 \%$ experienced a mental disorder within a 12-month period. ${ }^{4}$ In other studies, prevalence of anxiety/depression was found to range from 13\% to 19\% in Australia (general population), from $17 \%$ to $21 \%$ in Denmark (general practice population) and from $17 \%$ to $25 \%$ in the Netherlands (general and clinical practice populations of young male employees), which is lower than our meta-analyses showed among both current (34\%) and former (26\%) elite athletes. ${ }^{2}{ }^{21-53}$ Despite these figures, accurate comparison is difficult to make because the outcomes related to mental health symptoms and disorders were not measured using the same scales from one study to another. The slightly higher prevalence of mental health symptoms and disorders in current and former elite athletes than in the general population might be related to the sport-specific stressors likely to affect athletes during their career. ${ }^{6}$ Furthermore, the period of transitioning out of elite sport can be challenging for athletes. ${ }^{7}$ Involuntary retirement from sport, for instance as a consequence of an injury, as well as high levels of athletic identity, lack of retirement planning, lower educational attainment, post-sport unemployment and chronic pain, are all risk factors for post-career mental health symptoms and disorders. ${ }^{31} 323538404354-57$ Though the causal relationship remains unknown, the association between career-related concussions and post-sport mental health symptoms and disorders has been established in several studies among former elite athletes. ${ }^{363758-60}$

Despite the increasing number of scientific studies about mental health symptoms and disorders in elite sports, the authors believe that raising awareness about and prioritisation of mental health symptoms and disorders in elite sports should be undertaken by international and national stakeholders and federations. This is essential as the context of elite sports continues to struggle against the stigma associated with mental health symptoms and disorders. With regard to athlete support, as mental health symptoms and disorders are common in elite sports, availability of interdisciplinary medical care and support for elite athletes should be a minimum standard. To that end, sports medicine clinicians and licensed mental health professionals have a significant role to play in order to ensure timely diagnosis and provide elite athletes with appropriate management. Early diagnosis and proper treatment should serve to optimise sport performance and quality-of-life. Mental health symptoms and disorders in former elite athletes must also be addressed. After career consultation, as recently introduced in professional football as an 'exit health examination' focusing, among other issues, on the mental health of retired players, is an important concept. ${ }^{6162}$ Such an intervention was positively evaluated during a pilot study and should be made available for transitioning elite athletes, especially those experiencing involuntary sport retirement. ${ }^{62}$ Additionally, a thorough preparation for post-sport life could prevent the occurrence of mental health symptoms and disorders among former athletes, for instance through education programmes/ seminars, practical resource centres, and mental and life skills training for career transition. ${ }^{55}$

The main limitations of the studies included in our systematic review are that most relied primarily on a cross-sectional design and on self-reported data, while mental health symptoms and disorders were assessed with different scales not specifically developed and validated for the population of elite athletes. Longitudinal studies based on a prospective cohort design should be conducted over several years in order to explore the course of mental health symptoms and disorders in elite sports, and assess causal relationships between potential risk factors and outcome measures. The studies included in our meta-analyses focus on self-report mental health symptoms, but we strongly suggest that future studies also focus on clinical mental health disorders. Mental health disorders are typically defined as conditions causing clinically significant distress or impairment that meet certain diagnostic criteria, such as in the Diagnostic and Statistical Manual of Mental Disorders (DSM-5) or International Classification of Diseases (ICD), ${ }^{63}{ }^{64}$ whereas mental health symptoms are more common, may be significant, but do not occur in a pattern meeting specific diagnostic criteria and do not necessarily cause significant distress or functional impairment. The scales used in the included studies to measure mental health symptoms were generally different across studies. Additionally, studies largely focused on male elite athletes from team sports. Consequently, it is difficult to make valid comparisons across sports (eg, individual vs team sports), countries and culture (eg, Asian vs African athletes), genders and other demographic variables. This should be considered for future studies, with particular attention to enrolling female elite athletes (both during

\section{What we already know?}

- An elite sport career is characterised by more than 640 distinct stressors that could induce mental health symptoms and disorders.

- Transitioning out of sport can be a difficult period for athletes, with an increased likelihood of developing mental health symptoms and disorders.

- Mental health symptoms and disorders seem prevalent in current and former elite athletes.

\section{What are the new findings?}

- The prevalence of mental health symptoms and disorders in current elite athletes ranges from $19 \%$ for alcohol misuse to $34 \%$ for anxiety/depression.

- The prevalence of mental health symptoms and disorders in former elite athletes ranges from $16 \%$ for distress to $26 \%$ for anxiety/depression.

- The prevalence of mental health symptoms and disorders in current and former elite athletes may be slightly higher than in the general population, but it remains difficult to make valid comparisons. 
and after their career) as study populations. Furthermore, those scales used in the included studies were originally developed and validated in populations other than elite athletes. Therefore, further research should focus on the development of reliable and valid screening instruments for the specific population of elite athletes.

\section{CONCLUSION}

Our meta-analyses showed that the prevalence of mental health symptoms and disorders ranged from 19\% for alcohol misuse to $34 \%$ for anxiety/depression for current elite athletes, and from $16 \%$ for distress to $26 \%$ for anxiety/depression for former elite athletes. This justifies a minimum standard of care that provides elite athletes with access to interdisciplinary treatment teams who can make timely mental health diagnoses and implement management strategies that are amenable to this specific population. For former elite athletes, thorough preparation for postsport life is strongly suggested, and an 'exit health examination' could be beneficial.

\footnotetext{
Author affiliations

${ }^{1}$ Amsterdam UMC, Univ of Amsterdam, Department of Orthopaedic Surgery, Amsterdam Movement Sciences, Meibergdreef 9, Amsterdam, The Netherlands ${ }^{2}$ Amsterdam Collaboration on Health \& Safety in Sports (ACHSS), AMC/VUmc IOC Research Center of Excellence, Amsterdam, The Netherlands

${ }^{3}$ Department of Neuroscience, Medical School, Fundação do ABC, Santo André, Brazi ${ }^{4}$ Department of Psychiatry, Medical School, University of São Paulo, São Paulo, Brazil ${ }^{5}$ Sport and Exercise Science, University of Portsmouth, Portsmouth, UK

${ }^{6}$ National Collegiate Athletic Association (NCAA), Indianapolis, Indiana, USA

${ }^{7}$ Ebling Library for the Health Sciences, University of Wisconsin-Madison, Madison, Wisconsin, USA

${ }^{8}$ Amsterdam Center for Evidence-based Sports Medicine, Academic Medical Center, Amsterdam, The Netherlands

${ }^{9}$ Research and Translation, Orygen, The National Centre of Excellence in Youth Mental Health, Melbourne, Victoria, Australia

${ }^{10} \mathrm{Centre}$ for Youth Mental Health, University of Melbourne, Melbourne, Victoria, Australia

${ }^{11}$ Department of Psychiatry, University of Wisconsin School of Medicine and Public Health, Madison, Wisconsin, USA

${ }^{12}$ University Health Services, University of Wisconsin, Madison, Wisconsin, USA
}

Correction notice This article has been corrected since it first published online. The open access licence type has been amended.

Acknowledgements The authors thank the other participants in the 2018 International Olympic Committee Consensus Meeting on Mental Health in Elite Athletes, including Cindy Miller Aron, David Baron, Antonia Baum, Abhinav Bindra, Richard Budgett, Niccolo Campriani, Alan Currie, Jeff Derevensky, Lars Engebretsen, Ira Glick, Michael Grandner, Doug Hyun Han, David McDuff, Margo Mountjoy, Aslihan Polat, Rosemary Purcell, Margot Putukian, Allen Sills, Torbjorn Soligard, Todd Stull, Leslie Swartz and Li Jing Zhu, for their input on the development and interpretation of this research.

Contributors VG designed the study, reviewed identified papers and selected those matching inclusion criteria, coordinated the data extraction, assessed risk of bias, assisted in performing statistical analyses, edited and critically reviewed the manuscript, and approved the final version of the manuscript. JMC-M designed the study, performed the data extraction, edited and critically reviewed the manuscript, and approved the final version of the manuscript. PG designed the study, performed statistical analyses, edited and critically reviewed the manuscript, and approved the final version of the manuscript. BH designed the study, edited and critically reviewed the manuscript, and approved the final version of the manuscript. MH performed the literature searches, edited and critically reviewed the manuscript, and approved the final version of the manuscript. GK designed the study, reviewed identified manuscripts and selected those matching inclusion criteria, assessed risk of bias, edited and critically reviewed the manuscript, and approved the final version of the manuscript. SR designed the study, performed the data extraction, edited and critically reviewed the manuscript, and approved the final version of the manuscript. CR designed the study, edited and critically reviewed the manuscript, and approved the final version of the manuscript.

Funding The authors have not declared a specific grant for this research from any funding agency in the public, commercial or not-for-profit sectors.

Competing interests None declared.
Patient consent for publication Not required.

Provenance and peer review Not commissioned; externally peer reviewed.

Open access This is an open access article distributed in accordance with the Creative Commons Attribution 4.0 Unported (CC BY 4.0) license, which permits others to copy, redistribute, remix, transform and build upon this work for any purpose, provided the original work is properly cited, a link to the licence is given, and indication of whether changes were made. See: http://creativecommons.org/ licenses/by/4.0/.

\section{REFERENCES}

1. King M, Nazareth I, Levy G, et al. Prevalence of common mental disorders in general practice attendees across Europe. Br J Psychiatry 2008;192:362-7.

2. Korten $A$, Henderson $S$. The Australian national survey of mental health and well-being. Common psychological symptoms and disablement. Br J Psychiatry 2000;177:325-30.

3. Krueger RF, Caspi A, Moffitt TE, et al. The structure and stability of common mental disorders (DSM-III-R): a longitudinal-epidemiological study. J Abnorm Psychol 1998;107:216-27.

4. Steel Z, Marnane C, Iranpour C, et al. The global prevalence of common mental disorders: a systematic review and meta-analysis 1980-2013. Int J Epidemiol 2014:43:476-93.

5. Rice SM, Purcell R, De Silva $S$, et al. The mental health of elite athletes: a narrative systematic review. Sports Med 2016;46:1333-53.

6. Arnold R, Fletcher D. A research synthesis and taxonomic classification of the organizational stressors encountered by sport performers. J Sport Exerc Psychol 2012;34:397-429.

7. Wylleman P, Reints A. A lifespan perspective on the career of talented and elite athletes: perspectives on high-intensity sports. Scand J Med Sci Sports 2010;20(Suppl 2):88-94.

8. Moher D, Liberati A, Tetzlaff J, et al. Preferred reporting items for systematic reviews and meta-analyses: the PRISMA statement. BMJ 2009;339:b2535.

9. Hoy D, Brooks P, Woolf $A$, et al. Assessing risk of bias in prevalence studies: modification of an existing tool and evidence of interrater agreement. J Clin Epidemiol 2012;65:934-9.

10 Wallace BC, Schmid CH, Lau J, et al. Meta-Analyst: software for meta-analysis of binary, continuous and diagnostic data. BMC Med Res Methodol 2009:9:80.

11. DerSimonian R, Laird N. Meta-analysis in clinical trials. Control Clin Trials 1986:7:177-88.

12. Gouttebarge V, Aoki H, Kerkhoffs G. Symptoms of common mental disorders and adverse health behaviours in male professional soccer players. J Hum Kinet 2015;49:277-86

13. Gouttebarge $V$, Jonkers $R$, Moen $M$, et al. A prospective cohort study on symptoms of common mental disorders among Dutch elite athletes. Phys Sportsmed 2017:45:426-32.

14. Schuring N, Kerkhoffs G, Gray J, et al. The mental wellbeing of current and retired professional cricketers: an observational prospective cohort study. Phys Sportsmed 2017:45:463-9.

15. Biggins M, Cahalan R, Comyns T, et al. Poor sleep is related to lower general health, increased stress and increased confusion in elite Gaelic athletes. Phys Sportsmed 2018;46:14-20.

16. Drew M, Vlahovich $N$, Hughes $D$, et al. Prevalence of illness, poor mental health and sleep quality and low energy availability prior to the 2016 Summer Olympic Games. Br J Sports Med 2018:52:47-53.

17. Du Preez EJ, Graham KS, Gan TY, et al. Depression, anxiety, and alcohol use in elite rugby League players over a competitive season. Clin J Sport Med 2017:27:530-5.

18. Escobar-Molina R, Rodríguez-Ruiz S, Gutiérrez-García C, et al. Weight loss and psychological-related states in high-level judo athletes. Int I Sport Nutr Exerc Metab 2015;25:110-8.

19. Foskett RL, Longstaff F. The mental health of elite athletes in the United Kingdom. J Sci Med Sport 2018;21:765-70.

20. Giel KE, Hermann-Werner A, Mayer J, et al. Eating disorder pathology in elite adolescent athletes. Int. J. Eat. Disord. 2016:49:553-62.

21. Gouttebarge V, Tol JL, Kerkhoffs GMMJ. Epidemiology of symptoms of common menta disorders among elite Gaelic athletes: a prospective cohort study. Phys Sportsmed 2016;44:283-9.

22. Gouttebarge V, Aoki H, Verhagen EALM, et al. A 12-month prospective cohort study of symptoms of common mental disorders among European professional footballers. Clin J Sport Med 2017:27:487-92.

23. Gouttebarge V, Hopley P, Kerkhoffs G, et al. Symptoms of common mental disorders in professional rugby: an international observational descriptive study. Int J Sports Med 2017;38:864-70.

24. Gouttebarge V, Hopley P, Kerkhoffs G, et al. A 12-month prospective cohort study of symptoms of common mental disorders among professional rugby players. Eur J Sport Sci 2018;18:1004-12

25. Gulliver A, Griffiths KM, Mackinnon A, et al. The mental health of Australian elite athletes. J Sci Med Sport 2015;18:255-61. 
26. Håkansson A, Kenttä G, Åkesdotter C. Problem gambling and gaming in elite athletes. Addict Behav Rep 2018:8:79-84.

27. Hulley AJ, Hill AJ. Eating disorders and health in elite women distance runners. Int $J$ Eat Disord 2001:30:312-7.

28. Junge $A$, Feddermann-Demont N. Prevalence of depression and anxiety in top-level male and female football players. BMJ Open Sport Exerc Med 2016;2:e000087.

29. Schaal $K$, Tafflet $M, N a s s i f H$, et al. Psychological balance in high level athletes: gender-based differences and sport-specific patterns. PLOS ONE 2011:6:e19007.

30. Tan JOA, Calitri R, Bloodworth A, et al. Understanding eating disorders in elite gymnastics: ethical and conceptual challenges. Clin Sports Med 2016;35:275-92.

31. Brown JC, Kerkhoffs G, Lambert MI, et al. Forced retirement from professional rugby union is associated with symptoms of distress. Int I Sports Med 2017;38:582-7.

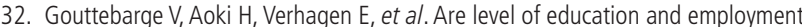
related to symptoms of common mental disorders in current and retired professional footballers? Asian J Sports Med 2016:7:e28447.

33. Gouttebarge V, Aoki H, Kerkhoffs GM. Prevalence and determinants of symptoms related to mental disorders in retired male professional footballers. J Sports Med Phys Fitness 2016;56:648-54.

34. Gouttebarge V, Kerkhoffs G, Lambert M. Prevalence and determinants of symptoms of common mental disorders in retired professional rugby union players. Eur I Sport Sci 2016;16:595-602.

35. Gouttebarge $V$, Jonkers $R$, Moen $M$, et al. The prevalence and risk indicators of symptoms of common mental disorders among current and former Dutch elite athletes. J Sports Sci 2017;35:2148-56.

36. Hart J, Kraut MA, Womack KB, et al. Neuroimaging of cognitive dysfunction and depression in aging retired National Football League players: a cross-sectional study. JAMA Neurol 2013;70:326-35.

37. Kerr ZY, Marshall SW, Harding HP, et al. Nine-year risk of depression diagnosis increases with increasing self-reported concussions in retired professional football players. Am I Sports Med 2012;40:2206-12.

38. Sanders G, Stevinson C. Associations between retirement reasons, chronic pain, athletic identity, and depressive symptoms among former professional footballers. Eur J Sport Sci 2017;17:1311-8

39. Schwenk TL, Gorenflo DW, Dopp RR, et al. Depression and pain in retired professional football players. Med Sci Sports Exerc 2007;39:599-605.

40. van Ramele S, Aoki H, Kerkhoffs GMMJ, et al. Mental health in retired professional football players: 12-month incidence, adverse life events and support. Psychol Sport Exerc 2017:28:85-90.

41. Willer BS, Tiso MR, Haider MN, et al. Evaluation of executive function and mental health in retired contact sport athletes. J Head Trauma Rehabil 2018;33:1-15.

42. Gouttebarge V, Frings-Dresen MHW, Sluiter JK. Mental and psychosocial health among current and former professional footballers. Occup Med 2015:65:190-6.

43. Gouttebarge V, Kerkhoffs GMMJ. A prospective cohort study on symptoms of common mental disorders among current and retired professional ice hockey players. Phys Sportsmed 2017:45:252-8.

44. Ö K, Aoki H, Haagensen R, et al. Symptoms of common mental disorders and related stressors in Danish professional football and handball. Eur J Sport Sci 2017;17:1328-34.

45. Engel $\mathrm{G}$. The need for a new medical model: a challenge for biomedicine. Science 1977:196:129-36.
46. Gouttebarge V, Aoki H, Ekstrand J, et al. Are severe musculoskeletal injuries associated with symptoms of common mental disorders among male European professional footballers? Knee Surg Sports Traumatol Arthrosc 2016;24:3934-42.

47. Kiliç Ö, Aoki H, Goedhart E, et al. Severe musculoskeletal time-loss injuries and symptoms of common mental disorders in professional soccer: a longitudinal analysis of 12-month follow-up data. Knee Surg Sports Traumatol Arthrosc 2018;26:946-54.

48. Li H, Moreland JJ, Peek-Asa C, et al. Preseason anxiety and depressive symptoms and prospective injury risk in collegiate athletes. Am J Sports Med 2017:45:2148-55.

49. Prinz B, Dvořák J, Junge A. Symptoms and risk factors of depression during and after the football career of elite female players. BMJ Open Sport Exerc Med 2016;2:e000124.

50. Rosenvinge J, Sundgot-Borgen J, Pettersen G, et al. Are adolescent elite athletes less psychologically distressed than controls? A cross-sectional study of 966 Norwegian adolescents. Open Access I Sports Med 2018;9:115-23.

51. Bültmann U, Kant I, KasI SV. Fatigue and psychological distress in the working population psychometrics, prevalence, and correlates. I Psychosom Res 2002;52:445-52.

52. Lynge I, Munk-Jørgensen P, Pedersen AL, et al. Common mental disorders among patients in primary health care in Greenland. Int I Circumpolar Health 2004;63:377-83.

53. Verhaak PF, Hoeymans N, Garssen AA, et al. Mental health in the Dutch population and in general practice: 1987-2001. Br J Gen Pract 2005;519:770-5.

54. Arvinen-Barrow M, Hurley D, Ruiz MC. Transitioning out of professional sport: the psychosocial impact of career-ending injuries among elite lrish rugby football union players. J Clin Sport Psychol 2017;11:67-84.

55. Knights S, Sherry E, Ruddock-Hudson M. Investigating elite end-of-athletic-career transition: a systematic review. J App/ Sport Psychol 2016;28:291-308.

56. Schuring N, Aoki H, Gray J, et al. Osteoarthritis is associated with symptoms of common mental disorders among former elite athletes. Knee Surg Sports Traumatol Arthrosc 2017;25:3179-85.

57. Wippert P-M, Wippert J. The effects of involuntary athletic career termination on psychological distress. J Clin Sport Psychol 2010;4:133-49.

58. Esopenko C, Chow TW, Tartaglia MC, et al. Cognitive and psychosocial function in retired professional hockey players. J Neurol Neurosurg Psychiatry 2017;88:512-9.

59. Gouttebarge $V$, Aoki H, Lambert M, et al. A history of concussions is associated with symptoms of common mental disorders in former male professional athletes across a range of sports. Phys Sportsmed 2017:45:443-9.

60. Guskiewicz KM, Marshall SW, Bailes J, et al. Association between recurrent concussion and late-life cognitive impairment in retired professional football players. Neurosurgery 2005;57:719-26.

61. Carmody S, Jones C, Malhotra A, et al. Put out to pasture: what is our duty of care to the retiring professional footballer? Promoting the concept of the 'exit health examination' (EHE). Br J Sports Med 2018;24. doi:10.1136/bjsports-2017-09839. [Epub ahead of print].

62. Gouttebarge V, Goedhart E, Kerkhoffs G. Empowering the health of retired professional footballers: the systematic development of an after career consultation and Its feasibility. BMJ Open Sport Exerc Med 2018;4:e00466.

63. American Psychiatric Association. Diagnostic and statistical manual of mental disorders (DSM-5). Washington, DC: American Psychiatric Publishing, 2013.

64. World Health Organization. International Classification of Diseases for mortality and morbidity statistics (ICD-11), 2018. Available: http://icd.who.int [Accessed 15 Jun 2018]. 